\title{
Planejamento e desenvolvimento de um ambiente virtual como instrumento de promoção regional e internacional do turismo
}

Planning and development a virtual environment as a tool of regional and international promotion of the tourism

Maria Elenita M. Nascimento ${ }^{1}$ Ariane Abrunhosa da Silva ${ }^{2}$

1 Pesquisadora associada sênior da UnB no Centro de Excelência em Turismo. É Ph.D em Computação pela University of Manchester-Inglaterra; Mestre em Ciências pelo Instituto de Pesquisas Espaciais (INPE-SP); Especialista em Gestão e Liderança Universitária, Universidade de Puebla, México. E.mails: elenita@unb.br, elenitan@gmail.com 2 Professora da Secretaria de Educação do DF e integrante do Grupo de Trabalho de implementação do Museu da Educação do DF (SEDF/UnB). Mestra em Turismo pela Universidade de Brasília. E.mails:ariane@unb. br;abrunhosa.ariane@gmail.com 


\section{Resumo}

Este artigo é decorrente de uma pesquisa aplicada realizada com o objetivo de conceber um paradigma de museu virtual, cujo planejamento e desenvolvimento contou com aportes conceituais, teóricos e empíricos dos campos do turismo e da museologia. O trabalho resultou na construção de um ambiente virtual, de modo a aproveitar o potencial da internet como hipermídia e suporte da oferta de informações, serviços e cenários promocionais da Capital da República como destino turístico. A metodologia utilizada é uma análise comparativa dos museus virtuais presentes na internet e complementada por fontes secundárias, de modo a se inferir um modelo de museu virtual, com uma aplicação prática: apresentar um acervo de informações e um acervo de imagens de uma cidadepatrimônio-cultural-da-humanidade que, sendo na realidade um museu a céu aberto, poderá ser visitada por meio da realidade virtual. A pesquisa gerou um produto - o Museu Virtual de Brasília - o qual pode tornar-se parâmetro para iniciativas semelhantes.

Palavras-chave: Museu virtual. Tecnologia da informação. Patrimônio cultural e inovação.

\section{Abstract}

The aim of this applied research is to design a virtual museum paradigm, which includes contributions on conceptual, theoretical and empirical fields of tourism and museology and planning and development for these areas The research resulted in the construction of a virtual environment, in order to harness the potential of hypermedia and the internet as support to offer information, services and promotional scenarios of the capital city of Brazil as a tourist destination. The methodology is a comparative analysis of Virtual Museums on the internet and complemented by secondary sources in order to infer a model of virtual museum with a practical application: to present a wealth of information and a collection of images of a city that, being actually a human cultural asset and open air museum, can be visited by means of virtual reality. The research generated as a product - the Virtual Museum of Brasilia - which can become a reference for similar initiatives.

Keywords: Virtual Museum; Information Technology, Cultural Heritage and Innovation 


\section{Introdução}

Brasília poderá se transformar em importante polo de atração, como prevê o Plano Nacional de Turismo (PNT, 2007-2010), desde que algumas estratégias sejam efetivadas, entre elas a elevação da cultura e do patrimônio histórico, artístico e cultural a patamares de distinção internacional. Mas, para isso, é preciso levar em consideração que uma cultura do turismo é consolidada por diversos fatores, entre eles, a valorização e preservação do patrimônio cultural e ambiental, meios de hospedagem, infraestrutura, engajamento dos vários atores sociais do turismo (governo, empresários e comunidade local), respeito às diferenças e a promoção ao diálogo intercultural.

A cidade que foi estrategicamente planejada para ser a nova Capital e parte de um desafio de interiorização do País aceito pelo presidente Juscelino Kubitschek, no início dos anos 1950, representa uma obra artística única. Concebida pelo urbanista Lucio Costa e pelo arquiteto Oscar Niemeyer, Brasília recebeu o título de Patrimônio Cultural da Humanidade da Organização das Nações Unidas para Educação, Ciência e Cultura (Unesco), no dia 7 de dezembro de 1987, em homenagem à riqueza e à singularidade dos vários aspectos do seu conjunto urbanístico, arquitetônico e paisagístico. Foi a primeira vez que um bem contemporâneo entrou na galeria dos monumentos universais.

No entanto, passados 53 anos da inauguração, a Capital não consegue estar presente no imaginário do povo brasileiro a ponto de gerar um fluxo de turismo mais intenso e permanente. Neste contexto, propôs-se o estudo e planejamento de um museu virtual, tendo como objetivo a preservação, a promoção e divulgação da Capital da República nos aspectos arquitetônicos, urbanísticos, históricos e culturais e, consequentemente, turísticos.

O Museu proposto tem caráter de uma galeria virtual, construída especialmente para abrigar várias exposições sobre Brasília. A ideia é apresentar uma sistematização das informações e encontrar a melhor maneira para apresentar as atrações turísticas e valorizar o plano urbanístico de Lucio Costa. Ou seja, o acervo do museu é a representação, no mundo virtual, de parte do patrimônio cultural inserido na maior área tombada do mundo, cuja extensão é de $11.225 \mathrm{~km}^{2}$. A essa área somam-se ainda algumas frações do território do Distrito Federal usado para fins de turismo como: O Parque Nacional de Brasília (conhecido como parque da Água Mineral), o prédio do Catetinho, O Museu Vivo da Memória Candanga, entre outros. Parte-se do princípio que a preservação de Brasília como Patrimônio Cultural da Humanidade é estratégica como um elemento de cidadania e identidade para os brasileiros.

Essa estrutura torna possível que milhares de pessoas em todo o mundo, que não costumam frequentar museus e galerias, possam partilhar do prazer de ver representada, de diversas formas, a capital brasileira, e assim despertar o desejo de 
conhecer in loco, a cidade considerada por seus habitantes, como um museu a céu aberto. Propõe-se ainda que o Museu Virtual seja uma fonte de informação, de pesquisa e divulgação de Brasília, permanentemente aberta ao público, em qualquer local do planeta. Considerando que os conteúdos serão traduzidos, isso possibilitará o acesso aos mais variados públicos internacionais, especialmente, para os novos e jovens consumidores de turismo, que se utilizam da internet para planejar suas viagens e anteverem os locais escolhidos para serem visitados.

Para tanto, tivemos como objetivo geral conceber e implementar um modelo de Museu Virtual, que seja também um centro de memória digital, com potencialidade de informar e divulgar Brasília, no Brasil e no Exterior, como a cidade que reuniu os princípios do urbanismo moderno no século XX. Mais especificamente, objetivamos também buscar compreender os aspectos conceitual, teórico e metodológico da correlação entre museologia e virtualidade aplicada ao turismo; realizar uma análise comparativa de experiências de museologia e virtualidade, levando em consideração a presença de elementos que se caracterizem como "indicadores de turisticidade" nos diferentes tipos de museus virtuais; realizar pesquisa com vistas à produção de um modelo de museu virtual para promoção de turismo; propor modelos de interface para um museu virtual e, em seguida, implementar um modelo de museu virtual (site).

Brasília é um objeto turístico, patrimonial, cultural, dotado de uma universalidade (reconhecida pela Unesco), embora permaneça como um tesouro oculto, em um mundo da hipervisibilidade permitida pelos meios de divulgação, em especial a internet. Nesse contexto, buscou-se nesta pesquisa, comprovar a viabilidade de um museu virtual - associado a uma cidade e a um objetivo de promoção do turismo. Para isso utilizou-se uma análise comparativa de museus virtuais presentes na internet e tendo como base a presença de indicadores de turisticidade, que são elementos que, estando presentes nos museus virtuais, servem tanto à museologia quanto ao turismo.

\section{Turismo cultural}

$\mathrm{Na}$ atualidade, as exigências mercadológicas impõem uma segmentação do mercado turístico, cada vez maior, com a intenção de identificar clientes com comportamentos semelhantes em relação a gostos, tempo de permanência e tipos de recursos envolvidos. Não falamos mais somente de turismo, mas de modalidades de turismo. Brasília tem se caracterizado como um destino de turismo de negócio, mas a beleza e a originalidade de sua arquitetura abrem a possibilidade de estimular um maior interesse por um turismo com características culturais que tenha seu foco no patrimônio arquitetônico e artístico. De acordo com Costa (2009): 
O objeto do turismo cultural é formado pelos elementos resultantes dos recursos culturais - materiais e imateriais - do local ou grupo visitado. Assim, os objetos que desencadeariam a visitação do turismo cultural seriam os bens originários da cultura e formadores do patrimônio cultural local visitado, em todos os seus múltiplos níveis.

Os bens materiais e imateriais (ou intangíveis) são objetos de estruturação de um turismo que visa levar o visitante a conhecer in loco estes recursos. No entanto, existem outras linhas de entendimento sobre turismo cultural, mas neste trabalho utilizou-se as concepções tradicionais que privilegiam o conhecimento de outras culturas por meio de seus bens culturais e na interação com outros grupos sociais e/ou com indivíduos de culturas diferentes.

Brasília é aqui percebida pela sua cultura, portanto, em um contexto de uma cidade que apresenta ao turista um diferencial em matéria de valores e ethos. Este diferencial consiste num valor específico, enquanto patrimônio cultural, sendo esse patrimônio organizado como um sistema, por sua vez, desdobrado em valores e símbolos: arquitetônicos, artísticos e, evidentemente, históricos. Nesta pesquisa escolheu-se trabalhar com a noção de cultura de Geertz (1978):

Acreditando, como Max Weber, que o homem é um animal amarrado a teias de significados que ele mesmo teceu, assume a cultura como sendo essas teias e sua análise; portanto, não como uma ciência experimental em busca de leis, mas sim uma ciência interpretativa, à procura do significado. É justamente explicações que se procura, analisando expressões sociais em sua enigmática superfície.

No caso de Brasília, muito antes das magníficas edificações tomarem forma, uma ideia ganhava corpo e se consolidava na medida em que se cultuou durante mais de dois séculos a proposta da mudança da Capital para o interior do País. Brasília, cidade com apenas cinco décadas, tem atrás de si uma arqueologia, a arqueologia de uma ideia, perseguida ao longo dos séculos. Com um discurso calcado pela necessidade de um lugar estrategicamente seguro, distante do mar e das possíveis invasões, com clima agradável e terras férteis, que possibilitassem o desenvolvimento do interior do país, a ideia da transferência amadurece e vai ganhando legitimidade institucional necessária para ser viabilizada. Pode-se dizer que houve um cultivo de um discurso mudancista, como nos lembra Queiroz (2003, p. 149):

[...] o valor intangível do bem patrimonial em Brasília vem antecipadamente na permanência da vontade política representada pelas decisões constitucionais, nos trabalhos das sucessivas missões de cientistas, técnicos e artistas na procura deste lugar escolhido, tudo antecedendo à materialização da obra que tornou realidade a imaterialidade do sonho, da utopia. 
Já o Museu Virtual de Brasília se insere dentro do contexto de ciberespaço e, se constitui como um instrumento cultural dentro desse espaço tecnológico. Logo, também é parte de uma forma de cultura, hoje conhecida como cibercultura. Desenhado na sua estrutura para funcionar, literalmente, como um "site" de cultura e, portanto, uma mídia cultural. No entanto, é um artefato que não veio totalmente dado culturalmente, como herança. E sim, um bem processual, em processo de cultivo.

Tal como a ideia da construção precisou ser cultivada, o Museu Virtual de Brasília, precisa cultivar seu acervo, ou seja, precisa estimular o cultivo do patrimônio cultural de Brasília, com sentido de ajudar a consolidar uma cultura referente ao valor simbólico da Capital para os brasileiros, como expressão de ousadia, de coragem, de criatividade nacional, como uma cidade que representa valores de nacionalidade e cidadania. Assim sendo, é preciso valorizar a história e a memória da cidade e de seus personagens e criar novos simbolismos relacionados à Capital da República. Pois é entre a cultura do que é socialmente dado como culto e a possibilidade de que 'novos' valores possam ser cultivados que se delineiam as brechas para que $o$ próprio espaço social seja dinâmico e aberto a intervenções.

Esse cultivo, por sua vez, implica a ideia de promoção ${ }^{3}$, conceito extremamente caro ao contexto de uma sociedade midiática e mercadológica e, portanto, sacudida em vários momentos pelas proposições que circulam num sistema de trocas. A mercadologia, como entendem os autores consagrados no campo do marketing, não se restringe às trocas mais primárias (compra e venda), mas, sobretudo, avança para a sofisticação das trocas simbólicas, de maneira que, mesmo quando se está literalmente vendendo alguma coisa, o que se vende não é a coisa em seu valor de uso, mas, sobretudo, em seu valor de troca, por exemplo, o prestigio ou status conferido a quem tem o carro do ano. Logo, o conceito de marketing precisa ser especificado, pois está se tratando de promoção de valores e ideias, deste modo, o marketing social, termo surgindo na década de 70, do século passado, para tratar de transformações de valores e comportamentos, talvez, seja o que mais se aproxima da intencionalidade deste trabalho.

Marketing social é uma estratégia de mudança de comportamento. Ele combina os melhores elementos das abordagens tradicionais da mudança social num esquema integrado de planejamento e ação, além de aproveitar os avanços na tecnologia das comunicações e na capacidade de marketing. "[...]. O abandono de uma ideia ou comportamento adverso ou a adoção de novas ideias e comportamentos é o objetivo do marketing social. $\mathrm{O}$ 'produto' a ser colocado no mercado são ideias e

3 Promoção: um conjunto de atividades de comunicação de marketing que visam fortalecer a imagem de uma marca, instituição ou individuo ou ainda, influenciar pessoas na escolha de determinado produto, serviço, comportamento (propaganda, relações públicas, marketing direto, venda pessoal. ((KOTLER, P.; ARMSTRONG, 2007). 
comportamentos" (KOTLER, 1992, p. 25-26)".

Para este trabalho importa o alcance social que os valores culturais, emanados do ambiente virtual, com o sentido de fortalecimento de um patrimônio cultural constituído, podem ter. Sendo assim, o marketing ganha a denominação de cultural, aquele que se encarrega especificamente de funcionar como estratégia de validação (legitimação coletiva) de propostas. E o P de promoção consequentemente estará a serviço da cultura (aquela que pode ser cultivada - promovida) e das mais variadas modalidades de cultura: no contexto aqui presente, a cultura do turismo.

\section{Patrimônio cultural}

A atualização da noção do patrimônio, tanto no plano internacional, como no plano nacional, termina sendo refletida na Constituição brasileira de 1988, fica explicitada no texto por meio do artigo $216^{4}$.

A Constituição faz referência a patrimônio cultural brasileiro, que, segundo o Iphan não se restringe apenas a imóveis oficiais isolados, igrejas ou palácios, mas na sua concepção contemporânea se estende a imóveis particulares, trechos urbanos e até ambientes naturais de importância paisagística, passando por imagens, mobiliário, utensílios e outros bens móveis. Considerando que este trabalho trata da representação de alguns elementos constitutivos de uma cidade, no espaço virtual, com fins de promoção turística e preservação patrimonial, escolheu-se um recorte patrimonial que fosse mais simbólico para Brasília. Assim, optou-se por uma noção de patrimônio cultural com foco na arquitetura e no urbanismo, especialmente, nas obras de Lucio Costa e Niemeyer, presentes na área tombada como Patrimônio Cultural da Humanidade. Mas não de uma forma estanque, pois está se trabalhando com objetivo de construir um museu virtual de uma cidade dinâmica. Logo, esses conteúdos serão apresentados dentro de um contexto de humanização, que fez parte da criação e da consolidação da Capital. Entendendo-se aqui como humanização, os valores históricos, estéticos, etnográficos e artísticos, entre outros. Valores estes que recheiam a cidade de sentidos e a fazem antes de ser um espaço turístico, se constituir em um espaço urbano que abriga várias funções, entre elas a de sediar as instituições administrativas e políticas do país.

4 Constituem patrimônio cultural brasileiro os bens de natureza material e imaterial, tomados individualmente ou em conjunto, portadores de referência à identidade, à ação, à memória dos diferentes grupos formadores da sociedade brasileira, nos quais se incluem: a) as formas de expressão; b) os modos de criar, fazer e viver; c) as criações científicas, artísticas e tecnológicas; d) as obras, objetos, documentos, edificações e demais espaços destinados às manifestações artístico-culturais; e) os conjuntos urbanos e sítios de valor histórico, paisagístico, artístico, arqueológico, paleontológico, ecológico e científico. 


\subsection{Memória coletiva}

Neste trabalho foi considerada a acepção referente à memória coletiva, ou seja, aquela que é parte de um determinado grupo social, que se expressa a partir de referências criadas e que são externalizadas e re-atualizadas por meio de símbolos e signos presentes num determinado contexto cultural. O conceito de memória social ou coletiva vem sendo trabalhado por vários autores, entre eles Pollak $(1989$, p. 3) que irá se apoiar em Maurice Halbwachs (La Mémoire Collective 1968):

Há diferentes pontos de referência que estruturam nossa memória e que a inserem na memória da coletividade a que pertencemos. Os monumentos são esses lugares da memória. O patrimônio arquitetônico e seu estilo, as paisagens, as datas e personagens históricos, as tradições e costumes, certas regras de interação, o folclore e a música, e também as tradições culinárias, enfim, todos esses elementos que nos acompanham por toda a nossa vida. Na tradição metodológica durkheimiana torna-se possível tomar esses diferentes pontos de referência como indicadores empíricos da memória coletiva de um determinado grupo, uma memória que ao definir o que é comum a um grupo e o que o diferencia dos outros, fundamenta e reforça os sentimentos de pertencimento e as fronteiras socioculturais.

O patrimônio entra como um elemento-chave de rememoração, ou seja, motivador de uma atualização da memória. Assim, no passado rememorado através dos ícones da beleza arquitetônica brasileira, encontra-se a Nova Capital, que possibilitou o desenvolvimento do interior do país, e representou um exemplo concreto da genialidade e da criatividade humana, uma prova clara da capacidade de vencer desafios do povo brasileiro, além da materialidade de um sonho, sonhado por muitos brasileiros. Deduz-se portanto, que o turismo, a memória e o patrimônio cultural andam juntos. E que a consolidação do turismo na Capital não pode relegar a necessidade de imprimir conteúdos históricos e culturais nas trilhas turísticas que se formam a partir do patrimônio de Brasília.

\section{Museu virtual: espaço de mediação}

Está surgindo dentro da museologia uma categoria totalmente nova de museus, com outras funcionalidades que vão além da salvaguarda dos bens patrimoniais e restauração de acervos. São essas funcionalidades que estão sendo descobertas e construídas nesse nosso momento histórico. Como esta modalidade de museu

é recente, há pouca literatura sobre o assunto, logo, as definições sobre museu virtual estão sendo amadurecidas e aprimoradas. Uma definição ampla e com base nas potencialidades de comunicação do ambiente virtual é expressa por Henriques 
(2004, p.11): “o museu virtual é um espaço virtual de mediação e de relação do patrimônio com os utilizadores. É um museu paralelo e complementar que privilegia a comunicação como forma de envolver e dar a conhecer determinado patrimônio".

No caso de um museu virtual de Brasília estaremos privilegiando exatamente essa relação entre um patrimônio e a mediação que se pode estabelecer com o público, com objetivo de ilustrar a importância histórica, artística e cultural desses bens para a construção de uma identidade nacional e para a cultura brasileira. Além disso, esta proposta tem especificidades muito próprias, no momento em que contempla a virtualização de um acervo material que está a céu aberto, inserido num contexto cultural e sua visitação deve ter como alvo os potenciais turistas.

Para o aprimoramento deste objetivo, levamos em conta o método de investigação em dois momentos. No primeiro momento, para investigação dos elementos de suporte à construção do modelo do Museu Virtual de Brasília foram utilizados os seguintes passos: análise comparativa de museus virtuais disponíveis na internet, com a intenção de buscar similaridades e diferenças entre os ambientes pesquisados, na sua relação com o turismo; definição da amostra - foram definidos quinze museus para compor a amostra que foi estruturada mediante as experiências de museus virtuais já existentes, preferencialmente entre aqueles que mais se aproximavam da temática da proposta de pesquisa: museus de arquitetura, artes, cidade, e de patrimônios mundiais ${ }^{5}$; e seleção de museus e criação de categorias (definidas por similaridade) para subdividir a amostra.

No segundo momento foram elencados os "Indicadores de turisticidade" para apoiar a análise. Esses indicadores foram apontados entre os elementos que, estando presentes nos museus virtuais, dessem suporte tanto à museologia quanto ao turismo. Ou seja, a suposição básica foi que eles pudessem ser utilizados para despertar o interesse turístico e servir de paradigmas na construção de um modelo de museu virtual, que tenha como acervo o patrimônio cultural de uma cidade. Os indicadores eleitos foram:

- a existência de um acervo material importante para ser visitado em um local/ prédio específico e com endereço relacionado no ambiente virtual;

- apresentação de funcionalidades como: exposições virtuais on line, fotografias 360 graus e/ou programas de fotos que reproduzam os objetos em vários ângulos (imagens em 3D), considerando que a utilização dessas funcionalidades sirva para tornar mais compreensível e atraente a visualização do acervo do museu;

5 São eles: 1) Museo Virtual de Artes /MUVA; 2) Museu Virtual de Arte brasileira; 3) Museum of Art modern (Moma); 4) The virtual Museum of Canadá; 5) The virtual Diego Rivera web museum; 6) European virtual museum; 7) Guggenheim; 8) The virtual museum Iraq; 9) Museu do Louvre; 10) Museu Nacional de Arqueologia; 11) Museu Virtual de Ouro Preto; 12) Sierra Nevada Virtual Museum; 13) Van Gogh Museum; 14) The Vatican museum; 15) Museu Virtual de Viana do Castelo. 
- a presença de informações explicativas sobre as peças dos acervos que são apresentados aos internautas que visitam esses museus (também chamado no turismo de interpretação do patrimônio e tem por base a filosofia interpretativa);

- o mecanismo de venda de ingressos (tickets) on line, para visitação ao museu, onde está localizado o acervo material; mecanismos para venda de tours turísticos relacionados ao universo temático do museu (dentro ou fora do museu) ou, ainda, outros tipos de tours turísticos e serviços que estimulem a ida ao local;

- ambiente com tradução para mais de uma língua, com vista à ampliação de público com interesse pelo tema tratado no museu;

- links e/ou disponibilização de informações sobre rede hoteleira local, Centro de Atendimento ao Turista (CAT), restaurantes, entre outros;

- indicações para outros museus, em outras cidades, ou referências para outros patrimônios com características semelhantes, que possam também ser visitados.

\subsection{Análise e comparação}

A análise e comparação dos dados demonstraram que existem elementos que servem bem, tanto à museologia quanto ao turismo, como apontam os indicadores de maior incidência. Estes indicadores referem-se às informações sobre os artefatos representados nos ambientes museológicos, a exemplo de legendas nas peças que estão em exposição. Também com um significativo número de incidência estão: os acervos importantes para serem visitados; exposições virtuais e funcionalidades, que auxiliam a apresentação dos acervos; e a tradução para outros idiomas.

Esses indicadores parecem ser parte de uma estrutura museológica virtual que está sendo construída e que aos poucos se consolida. Com uma presença tímida, estão os mecanismos de venda de ingressos, de tour turístico e sugestões de outros espaços culturais a serem visitados. A indicação de hotéis, restaurantes e outros serviços turísticos no ambiente museológico virtual foram observados em apenas dois museus virtuais. A partir dos resultados foram gerados subsídios para o desenvolvimento de um modelo do referido Museu Virtual de Brasília.

\section{Museu Virtual de Brasília}

Esta seção apresenta uma sequência de sugestões de interfaces, fruto dos resultados da pesquisa, que reunidas a todas as outras recomendações, podem ser utilizadas no desenvolvimento de um ambiente com as características de um museu virtu- 
al que sirva também ao turismo. Pode-se dizer que "modelos" são representações e estruturação de ideias, conhecimentos, sistemas e fenômenos, com a finalidade de: visualizar o que foi idealizado; prevenir e detectar problemas; explicar a ideia para quem vai desenvolver/construir (técnicos); testar o funcionamento; e providenciar pequenos ajustes com objetivo de aprimoramento e economia de recursos.

Os modelos de interface aqui apresentados seguem uma concepção pedagógica, com vista a proporcionar um primeiro entendimento do ambiente proposto. São apresentadas somente as páginas principais. A figura 1 apresenta a abertura do museu virtual de Brasília, cujo endereço é: www.museuvirtualbrasilia.org.br

\section{Figura 1 - Imagem da abertura do MVB}

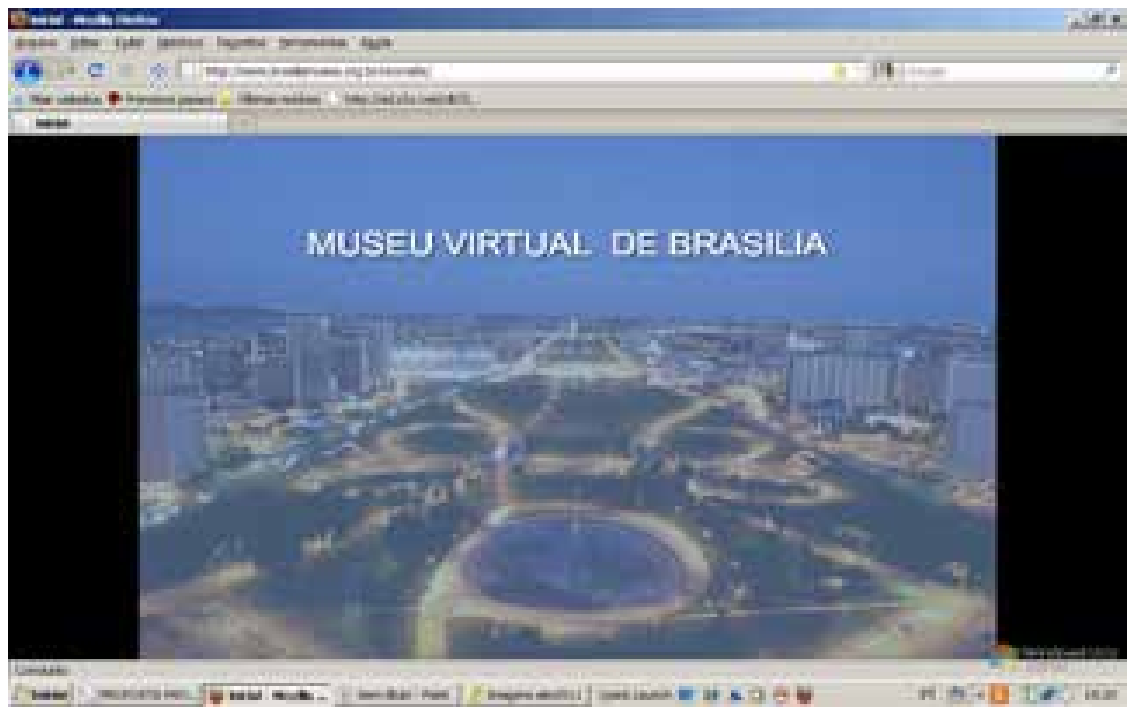

Escolheu-se propositadamente não utilizar uma abertura mais elaborada, devido a dois fatores: o tempo de espera para carregar o programa; ausência de tempo livre e a quantidade de informações disponíveis hoje na rede. Então, a opção foi por uma imagem transparente, em azul, que se reparte e deixa livre a visualização da imagem da página principal. $O$ azul foi escolhido em uma alusão ao céu de Brasília, considerada a mais linda beleza natural da Capital. A Figura 2 apresenta a página principal do museu que é constituída de dois menus na vertical, sendo o menu principal do ambiente e um menu secundário, onde o internauta tem acesso às fotografias em 360 graus. 


\section{Figura 2 - Página principal do MVB}

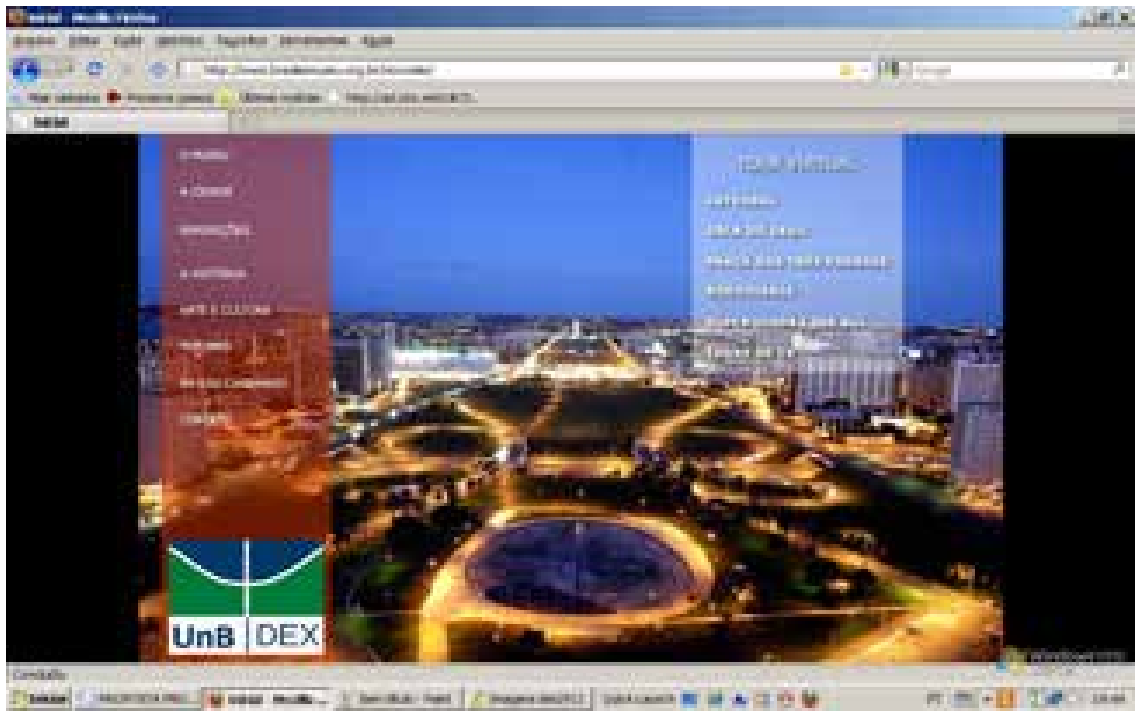

Escolheu-se colocar as imagens em 360 graus, na primeira página, por se tratar de um recurso importante para o turista que deseja visualizar a cidade da forma mais realista possível. A opção por uma construção baseada em informações imagéticas também trouxe a decisão do uso de uma fotografia do Eixo Monumental com vista do Congresso Nacional e a amplidão do céu, no fundo da página. O menu principal se divide em: O Museu; A Cidade; Exposições, A História, Arte e Cultura, Turismo; Eu sou Candango; Contato e por último as logomarcas dos patrocinadores que se intercalam, num espaço de tempo de segundos.

\section{Considerações finais}

A pesquisa apresentou a concepção de um museu virtual como centro de memória digital, com potencialidade de informar e divulgar Brasília, no Brasil e no exterior, como a cidade que reuniu os princípios do urbanismo moderno, no século XX. Poderá, no entanto, com as adaptações necessárias, servir de paradigma para outras cidades e regiões, como já acontece no exterior, onde cidades se articulam para o funcionamento de museus consorciados.

Conclui-se que a internet e sua prática de digitalização e publicização das informações em todos os setores, também atingiram o turismo e as mais diversas formas de sua promoção, dentre elas a museologia virtual. Os "indicadores de turisticidade" inferidos comprovaram o que prevíamos e ajudaram a construir uma representação 
do patrimônio, organizada de forma a servir tanto ao turismo quanto à museologia. Uma representação fundamental para construção de uma memória social da cidade e para atualização dessa memória. Essa representação colaborou para diminuir a intangibilidade do turismo e para a promoção de valores relacionados à consolidação de uma cidade como patrimônio cultural. Como acontece nos espaços museológicos tradicionais, que também são turísticos e onde o público é o elemento essencial para as duas atividades, no ciberespaço as complementaridades são alargadas, pois se trata de um extenso suporte e de uma hipermídia, com poder de comunicação em todo mundo.

"Musealizar" um espaço urbano não significa torná-lo fixo no tempo, até mesmo porque isto seria inviável, levando em consideração que as próprias definições do que é tido como museu estão em constantes atualizações. Espera-se que o Museu Virtual de Brasília auxilie outras concepções de comunicação cultural, onde a utilização do patrimônio deve ser um recurso educacional e turístico, entre tantas outras possibilidades. Mas para que isto aconteça, o patrimônio precisa ser cuidado, preservado e valorizado.

Um museu virtual demanda uma prática cotidiana que associe pesquisas, preocupação com a formação de acervo, salvaguarda (conservação e documentação) e comunicação (exposição e educação). E tudo isso, sempre levando-se em conta as necessárias adequações às formas apropriadas ao meio digital. Uma simples cópia do que é realizado nos museus tradicionais pouco valeria para a consolidação de um espaço museológico virtual, que requer uma especificidade própria, ou seja, precisa encontrar soluções adequadas ao meio e à proposta em questão.

Uma saída natural pode ser como já acontece em cidades mais antigas, ou seja, a tendência da área tombada passar a funcionar como centro histórico, seguindo exemplos de cidades como Goiás e Ouro Preto, onde esses centros proporcionam uma religação histórica e estética com o passado e ainda dispondo de uma revitalização plena, com potencialidade de atração turística. Um segundo passo, no entanto, poderá ser a transposição desses verdadeiros museus a céu aberto para o ciberespaço e, dele, para o imaginário das pessoas que sonham com destinos turísticos e os elegem a partir de referências, de informações e de serviços, elementos que um museu virtual pode oferecer.

Evidentemente, que somente imagens bonitas e informações correspondentes não funcionarão, se uma série de providências não forem paralelamente adotadas. Uma realidade destoante dos atrativos visualizados na internet pode repercutir como publicidade enganosa, o que, em termos de marketing, pode se transformar 
em fiasco, além de ser algo condenado pelos códigos de autorregulamentação publicitária e de defesa do consumidor.

De imediato, acreditamos que o Museu Virtual de Brasília pode render projeções para a própria região envolvida, já que o Entorno do DF é riquíssimo em cidades históricas e patrimônios naturais e ecológicos, a exemplo das famosas cachoeiras situadas nos municípios de Corumbá e Alto Paraíso. No entanto, nada impede que cidades e regiões diversas se associem para a utilização de projetos cooperados de museus virtuais para a promoção do turismo, especialmente, do turismo com ênfase em história, meio ambiente, cultura e arte.

\section{Referências}

COSTA, Flávia Roberta. Turismo e Patrimônio Cultural: interpretação e qualificação. São Paulo: Editora Senac, 2009.

GEERTZ, C. A Interpretação das Culturas. Rio de Janeiro: Zahar Editores, 1978.

HALBWACHS, M. La mémoire collective. Paris, PUF, 1968.

HENRIQUES, Rosali. Memória, museologia e virtualidade: um estudo sobre o Museu da Pessoa. Dissertação defendida na Universidade Lusófona de Humanidades e Tecnologia, de Lisboa, 2004.

KOTLER, P.; ROBERTO, E. Marketing Social: uma estratégia para alterar o Comportamento Público. Tradução José Ricardo Azevedo e Elizabethe Maria Braga - Editora Campus, 1992.

PLANO NACIONAL DE TURISMO (PNT). Disponível em: http://www.turismo.gov.br/ turismo/o_ministerio/plano_nacional/index.html. Acessado em: 03.01.2011.

POLLAK, M - Memória, Esquecimento e Silêncio. Em: Estudos Históricos, Rio de Janeiro, vol. 2, n. 3, $1989-$ p.3-15.

QUEIROZ, Cláudio José Pinheiro Villar de. Brasília: "Arquitectónica" intercultural, herança e síntese de modernidade (re)voluta, ou aforismo sobre a ética no espaço. Tese de Doutorado, Centro de Desenvolvimento Sustentável, Universidade de Brasília, 2003. 